\title{
The Effects of Gum Cordia on the Physicochemical, Textural, Rheological, Microstructural, and Sensorial Properties of Apple Jelly
}

\author{
Mahsa Hasani and Sedigheh Yazdanpanah \\ Department of Food Science and Technology, Kazerun Branch, Islamic Azad University, Kazerun, Iran \\ Correspondence should be addressed to Sedigheh Yazdanpanah; yazdanpanah2004@gmail.com
}

Received 13 July 2020; Revised 2 August 2020; Accepted 8 August 2020; Published 17 August 2020

Academic Editor: Chunpeng Wan

Copyright (c) 2020 Mahsa Hasani and Sedigheh Yazdanpanah. This is an open access article distributed under the Creative Commons Attribution License, which permits unrestricted use, distribution, and reproduction in any medium, provided the original work is properly cited.

\begin{abstract}
The aim of this research was to study the effects of gum cordia on the physicochemical, color, textural, rheological, microstructural, and sensorial properties of apple jelly. Apple jelly was prepared by replacement of 0,25, 50, 75, and 100\% of pectin with gum cordia. The results showed that gum cordia had a significant effect on the physicochemical properties (ash, protein, TPC, DE, and color) of apple jelly. The total phenol content of the sample significantly increased with the addition of gums. The rheological properties showed that a sample containing $75 \%$ gum cordia was similar to control and had the highest apparent viscosity, loss moduli $\left(G^{\prime \prime}\right)$, storage moduli $\left(G^{\prime}\right)$, and complex viscosity. Also, the sensorial properties showed that a sample containing $75 \%$ gum cordia had a high score in texture, taste, appearance, and overall acceptability. The results suggested that gum cordia as a polymer can be successfully employed for the formulation of jelly for improving technofunctional properties of jelly.
\end{abstract}

\section{Introduction}

Gum cordia is an anionic polysaccharide containing uronic acid and it is extracted from Cordia myxa fruit [1]. This gum has some technofunctional properties such as good emulsifying and binding properties [2]. Also, the application of this gum as a novel nanoparticle for drug delivery has been evaluated [3]. Some other applications including production of paper and cardboard were reported previously [4]. Haq et al. [4] studied the effects of gum cordia as an antioxidant carrier for improving shelf life of nuts. Gum cordia has pseudoplastic behavior with a high viscosity so its strong emulsifier, thickener, and stabilizer in food industry and pharmaceutical technology [5].

Today, there is a lot of research on the application of fruits for improving body health. They reported fruit consumption reduced obesity, diabetes, and cardiovascular disease. The health properties of fruits are related to the high content of antioxidant ingredients such as phenolic acids and vitamins. On the other hand, the shelf life of some fruits is very low and they are perishable, so researchers try to convert fruits to some products such as jelly and jam. Jelly is a product containing fruit juice, gelator, sugar, and acid and it has a firm structure [6]. Apple fruit is a good source of nutritional ingredients such as phenolic acids, organic acids, minerals, and reducing sugars [7]. Also, it is a rich source of vitamins including ascorbic acid [8] and it has antioxidant ingredients [9].

The first production of jelly was based on the highmethoxyl pectin and it was a firm gel with $2.8-3.5 \mathrm{pH}$ and containing $55 \%$ soluble solid components. $\mathrm{pH}$ was a very important parameter in the production of gel in the convectional jelly due to the high application of pectin. The production of jelly with low methoxyl pectin needs some other ingredients such as bivalent ions. Today's application of hydrocolloids for production of jelly was increased. Some main parameter of hydrocolloids such as creating viscosity, texture, and structure in final products are important. Hydrocolloids can hold water in their structure and improve viscosity and gel structure [10-12]. One of the attractive 
fields in the production of jelly is the application of a mixture of hydrocolloids in the jelly and researchers try to improve functional properties of products with a combination of pectin and hydrocolloids $[13,14]$.

The aim of our research was to determine the effects of gum cordia on the physicochemical (moisture, protein, ash, carbohydrate, fiber, sugar, total phenolic content, $\mathrm{pH}$, and $\mathrm{DE}$ ), color ( $L, a, b, \Delta \mathrm{E}$ and $\mathrm{YI}$ ), rheological (viscosity and rheometry parameters), and sensorial properties of apple jelly.

\section{Material and Methods}

2.1. Material. Apples were bought at a local market (Shiraz, Iran) and stored at $5^{\circ} \mathrm{C}$ during $48 \mathrm{~h}$ prior to juice extraction. Pectin, HM (green ribbon) which is high-methoxyl, pectin (DE $\sim 60 \%$ ), was obtained from Obipektin (Bischofszell, Switzerland). All other chemicals were bought from Merck (Darmstadt, Germany).

2.2. Gum Extraction. The extraction of gum from fruit was done by the method described by Haq et al. [4] with some minor modifications. Fruits were added to hot double distilled water $\left(85^{\circ} \mathrm{C}\right)$ containing $1000 \mathrm{ppm}$ of sodium metabisulfite in $1: 4$ ratio and stirred for $35 \mathrm{~min}$. The suspension was filtered completely by a cloth. The separated liquid was centrifuged at $6000 \mathrm{~g}$ for $50 \mathrm{~min}$. The gum was precipitated from clear supernatant by application of $\mathrm{HCl}$ in $1: 100$ ratio. Finally, the mixture was centrifuged at $3000 \mathrm{~g}$ for $15 \mathrm{~min}$. The precipitate of the sample was washed with double distilled water for 3 times. The extracted gum freeze-dried and then completely ground to 60 mesh sieve and kept at $5^{\circ} \mathrm{C}$ until experiments.

2.3. Jelly Preparation. Apple juice was produced by hand peeling of apples and extracting with a juice maker. The main components of apple jellies were apple juice $(900 \mathrm{~mL})$, sucrose $(80 \mathrm{~g})$, and gelator $(20 \mathrm{~g})$. To create a good texture by pectin and setting $\mathrm{pH}$, citric acid $(2.7 \mathrm{~g})$ was added. The best $\mathrm{pH}$ value for creating a good texture by pectin is 2.9 to 3.1 , so $\mathrm{pH}$ of samples was set at 3 . Apple juice, $60 \mathrm{~g}$ of sugar, and citric acid were homogenized and heated at $85^{\circ} \mathrm{C}$. Then, gelator and $20 \mathrm{~g}$ sugar was homogenized and added to the suspension at the end of jelly cooking. Apple jelly suspension was heated to final soluble solids of jelly arrived at $66.8 \%$. The time of heating was around $0.5 \mathrm{~h}$. Final products were poured into the cups and kept at $5^{\circ} \mathrm{C}$. Apple jellies were produced by replacement of $0,25,50,75$, and $100 \%$ of pectin with gum cordia as a gelator.

2.4. Chemical Composition Measurement. The moisture content of the sample was measured by the application of vacuum oven drier at 70 vacuum oven [15]. Ash, protein, carbohydrate, and fiber content were determined based on AOAC standard method [16].
2.5. Sugar Content Measurement. The percent of total reducing sugars was measured by the application of Fehling's $\mathrm{A}$ and $\mathrm{B}$ solution methods. The methylene blue was used as an indicator [17].

2.6. Total Phenol Content (TPC) Measurement. TPC of jellies was determined based on the method of Kopjar et al. [6] with some minor modifications. First, $200 \mathrm{mg}$ of sample and $1.8 \mathrm{~mL}$ DDW were completely mixed, and then $10 \mathrm{~mL}$ of Folin-Ciocalteu reagent $(10 \% \mathrm{w} / \mathrm{w})$ and $8 \mathrm{~mL}$ of sodium carbonate solution $(7.5 \% \mathrm{w} / \mathrm{w})$ were added to it. The suspension was kept at $25^{\circ} \mathrm{C}$ for $120 \mathrm{~min}$ in a dark condition (to complete reaction). The absorbance of sample and control was measured by a UV-spectrophotometer at $764 \mathrm{~nm}$. Gallic acid was used as a standard and our results were reported based on $\mu \mathrm{g}$ of gallic acid per g of jelly $\left(\mu \mathrm{g} \cdot \mathrm{GAE} \cdot \mathrm{g}^{-1}\right)$.

2.7. $\mathrm{pH}$ Measurement. For the determination of the $\mathrm{pH}$ value of samples, $1 \mathrm{~g}$ of jelly was homogenized with $9 \mathrm{~mL}$ DDW at $51^{\circ} \mathrm{C}$ using a mixer. The $\mathrm{pH}$ value of the sample was determined by a pH meter (OHAUS, Switzerland) [18].

2.8. Degree of Esterification Measurement. A titration technique based on the modified method of Pinheiro et al. [19] was used for the determination degree of esterification (DE). $0.4 \mathrm{~g}$ of dried sample wetted with ethanol in a bottle, and it was mixed with $40 \mathrm{~mL}$ DDW at $37^{\circ} \mathrm{C}$. Samples were stirred for $120 \mathrm{~min}$ to completely dissolve. The resulting suspension neutralized by $\mathrm{NaOH}(100 \mathrm{mM})$ and the volume of $\mathrm{NaOH}$ was recorded (A) (in this part phenolphthalein was used as an indicator). Then, $20 \mathrm{~mL}$ of $\mathrm{NaOH}$ solution $(100 \mathrm{mM})$ was mixed with samples and kept in $25 \mathrm{C}$ for $120 \mathrm{~min}$ to saponify the esterified carboxyl groups of the samples. Then, $20 \mathrm{~mL}$ $\mathrm{HCl}(100 \mathrm{Mm})$ was added and mixed. Finally, titration of samples was done by $\mathrm{NaOH}(100 \mathrm{mM})$ and the volume of it was recorded (B). Esterified carboxy groups number was determined based on the following equation:

$$
\mathrm{DE}=\frac{\mathrm{B}}{(\mathrm{B}+\mathrm{A})} 100
$$

2.9. Color Parameters Measurement. The surface color parameters of samples were determined using the CIELAB system (CR-410, Japan). $L *, a *, b *, \Delta \mathrm{E}$, and YI of samples were reported as the main parameters in jelly. The $L *$ (black (0) to white $(100)), a *($ red $(+100)$ to green $(-100)), b *$ (yellow $(+100)$ to blue $(-100)$ ) indicate the color of samples. $\triangle \mathrm{E}$ and $\mathrm{YI}$ were calculated based on Lab parameters [20].

2.10. Rheological Properties Measurement. Elastic ( $\left.\mathrm{G}^{\prime}\right)$, viscous $\left(G^{\prime \prime}\right)$ moduli, Tan $\delta$, and complex viscosity of jellies at $25^{\circ} \mathrm{C}$ were measured by a plate geometry (diameter $d=50 \mathrm{~mm}$, gap $=2 \mathrm{~mm}$ ). Dynamic oscillatory test of jellies at angular frequencies $(\omega)$ from 0.628 to $62.8 \mathrm{rad} / \mathrm{s}$ in the linear viscoelastic range (LVR) at $0.5 \%$ strain. Rheological parameters were determined in a Paar Physica MCR 301 
TABLE 1: The effects of pectin: gum ratio on the moisture, ash, protein, carbohydrate, and fiber content of samples.

\begin{tabular}{lcccrr}
\hline & Moisture content & Ash & Protein & Carbohydrate & Fiber \\
\hline P50G50 & $74.00 \pm 0.58 \mathrm{~A}$ & $0.31 \pm 0.01 \mathrm{~B}$ & $0.30 \pm 0.05 \mathrm{C}$ & $23.20 \pm 0.69 \mathrm{~A}$ & $0.22 \pm 0.01 \mathrm{~A}$ \\
P75G25 & $76.30 \pm 0.98 \mathrm{~A}$ & $0.36 \pm 0.03 \mathrm{C}$ & $0.23 \pm 0.01 \mathrm{~B}$ & $23.00 \pm 0.52 \mathrm{~A}$ & $0.20 \pm 0.01 \mathrm{~A}$ \\
P25G75 & $74.10 \pm 1.61 \mathrm{~A}$ & $0.27 \pm 0.02 \mathrm{~B}$ & $0.32 \pm 0.04 \mathrm{C}$ & $22.70 \pm 0.87 \mathrm{~A}$ & $0.21 \pm 0.05 \mathrm{~A}$ \\
P100 & $74.50 \pm 1.50 \mathrm{~A}$ & $0.43 \pm 0.05 \mathrm{D}$ & $0.18 \pm 0.02 \mathrm{~A}$ & $24.87 \pm 0.58 \mathrm{~B}$ & $0.22 \pm 0.00 \mathrm{~A}$ \\
G100 & $76.50 \pm 1.50 \mathrm{~A}$ & $0.21 \pm 0.01 \mathrm{~A}$ & $0.37 \pm 0.04 \mathrm{C}$ & $22.77 \pm 0.58 \mathrm{~A}$ & $0.20 \pm 0.01 \mathrm{~A}$ \\
\hline
\end{tabular}

${ }^{*}$ Data represent the means of three independent repeated \pm standard deviation. ${ }^{*}$ Capital letters in each column showed significant differences $(P<0.05)$. * P50G50 (sample containing 50\% pectin and 50\% gum); P75G25 (sample containing 75\% pectin and 25\% gum); P25G75 (sample containing 25\% pectin and 75\% gum); P100 (sample containing 100\% pectin) and G100 (sample containing 100\% gum).

rheometer (Anton Paar GmbH, Graz, Austria), with controlled temperature (Viscotherm VT2, Phar Physica) [21].

2.11. Viscosity Measurement. The rheological behavior of samples was measured at $25^{\circ} \mathrm{C}$ and the shear rate range of 0.01-93.9 s ${ }^{-1}$ using an Anton Paar rheometer (MCR 302, Graz, Austria). Cone-plate geometry (type CP25-1) with $25 \mathrm{~mm}$ cone diameter and $0.052 \mathrm{~mm}$ gap size at $1^{\circ}$ cone angle was used. System temperature was controlled by a Peltier system with an accuracy of $0.1^{\circ} \mathrm{C}$. The apparent viscosity was determined at the shear rate of $19.1 \mathrm{~s}^{-1}$.

2.12. Textural Properties. Textural features of the samples were investigated using a texture analyzer (Brookfield, USA) by a double compression test. 2.5 (diameter) $\times 1$ (height) $\mathrm{cm}$ cylinder of each sample was compressed to $40 \%$ penetration depth with $5 \mathrm{~mm} / \mathrm{s}$ pretest speed and $0.5 \mathrm{~mm} / \mathrm{s}$ test speed using a cylinder probe of $25 \mathrm{~mm}$ diameter.

2.13. Microstructure. The surface morphology of the sample was analyzed by a scanning electron microscope (TESCAN Vega3, Czech Republic). Freeze-dried samples were covered with a thin layer of gold (Desk Sputter Coater DSR1, Nanostructural Coating Co., Iran). Micrographs were taken at an accelerating voltage of $20 \mathrm{kV}$ [22].

2.14. Sensorial Properties Measurement. Sensorial properties of samples were determined based on five-point hedonic test described by [18] with some minor modification. Appearance, texture, taste, odor, and overall of jellies was evaluated from 1 (disliked extremely) to 5 (liked extremely) score. The sample was consumed by 10 semitrained student (male and female from 22 to 30 years) of the Department of Food Science and Technology of Kazerun Azad University, Iran. Jellies coded at random order and placed on plates with a glass of water. The study was done on a white bench under the usual light at $20^{\circ} \mathrm{C}$.

2.15. Statistical Analysis. Averages and standard deviations of samples were reported based on the triplicate measurement. One-way analysis of variance (ANOVA) and Duncan's Multiple Range Test were used for comparing the averages at 5 percent significant level. The statistical analysis was done by SPSS 19 software (SPSS, IBM, Chicago, IL, USA).
TABLE 2: The effects of pectin: gum ratio on the total phenol content, $\mathrm{pH}$, sugar content, and DE of samples.

\begin{tabular}{lcccc}
\hline & TPC & $\mathrm{pH}$ & $\begin{array}{c}\text { Sugar } \\
\text { content }\end{array}$ & $\mathrm{DE}$ \\
\hline P50G50 & $26.80 \pm 1.15 \mathrm{D}$ & $4.21 \pm 0.48 \mathrm{~A}$ & $21.00 \pm 0.87 \mathrm{~A}$ & $83.70 \pm 0.81 \mathrm{~B}$ \\
P75G25 & $19.00 \pm 0.52 \mathrm{~B}$ & $4.28 \pm 0.28 \mathrm{~A}$ & $21.30 \pm 0.75 \mathrm{~A}$ & $84.40 \pm 0.58 \mathrm{~B}$ \\
P25G75 & $23.30 \pm 0.75 \mathrm{C}$ & $4.08 \pm 0.20 \mathrm{~A}$ & $20.40 \pm 0.81 \mathrm{~A}$ & $82.20 \pm 0.52 \mathrm{~A}$ \\
P100 & $11.80 \pm 1.04 \mathrm{~A}$ & $4.40 \pm 0.06 \mathrm{~A}$ & $20.50 \pm 1.15 \mathrm{~A}$ & $86.60 \pm 0.64 \mathrm{C}$ \\
G100 & $34.70 \pm 1.44 \mathrm{C}$ & $3.90 \pm 0.40 \mathrm{~A}$ & $22.60 \pm 1.38 \mathrm{~A}$ & $81.80 \pm 0.46 \mathrm{~A}$
\end{tabular}

${ }^{*}$ Data represent the means of three independent repeats \pm standard deviation. ${ }^{*}$ Capital letters in each column showed significant differences $(P<0.05) .{ }^{*}$ P50G50 (sample containing $50 \%$ pectin and $50 \%$ gum); P75G25 (sample containing $75 \%$ pectin and $25 \%$ gum); P25G75 (sample containing $25 \%$ pectin and $75 \%$ gum); P100 (sample containing $100 \%$ pectin) and G100 (sample containing $100 \%$ gum).

\section{Results and Discussion}

3.1. Chemical Composition. The results of the chemical composition of apple jellies, including moisture, ash, protein, carbohydrate, and fiber content are reported in Table 1. Moisture content is a key quality factor in the packed food products such as jellies. It has some effects on the microbial quality and stability parameters of products [23]. Table 1 reports that there are no significant differences between the moisture content of samples. Mutlu et al. [18] reported that gelatin dose had not significantly $(P>0.05)$ influence the moisture content of different honey jelly candies. The presence of biopolymers has a significant effect on the water holding capacity of jelly samples [24]. The protein content of samples significantly increased with the addition of gum concentration. This is due to the protein content of gum cordia. The protein content of this gum was reported around 2 to $9 \%[25,26]$. The results showed that a sample containing $100 \%$ pectin had the highest carbohydrate content. The ash content of samples significantly decreased with the addition of gum concentration. There were no significant differences between the fiber content of the samples. The low changes in some composition ingredients are due to the differences between pectin and gum composition. Pectin is a pure ingredient but gum cordia contains protein and fiber.

3.2. Sugar Content, Total Phenol Content, $p H$, and DE. The results of TPC, $\mathrm{pH}$, sugar content, and DE are shown in Table 2 . The total phenol content of the sample significantly increased with the addition of gum concentration. There is some research that reported gum cordia had some phenolic 
TABLE 3: The effects of pectin: gum ratio on the color properties of samples.

\begin{tabular}{lccccc}
\hline & $L$ & $a$ & $b$ & $\Delta \mathrm{E}$ & YI \\
\hline P50G50 & $30.00 \pm 0.58 \mathrm{~A}$ & $11.67 \pm 0.33 \mathrm{~A}$ & $24.67 \pm 1.33 \mathrm{~A}$ & $74.43 \pm 0.51 \mathrm{~A}$ & $117.47 \pm 4.95 \mathrm{~B}$ \\
P75G25 & $31.33 \pm 0.33 \mathrm{AB}$ & $11.67 \pm 0.88 \mathrm{~A}$ & $25.00 \pm 0.58 \mathrm{~B}$ & $76.49 \pm 0.22 \mathrm{~B}$ & $113.99 \pm 5.11 \mathrm{~B}$ \\
P25G75 & $29.33 \pm 1.45 \mathrm{~A}$ & $12.33 \pm 0.33 \mathrm{~A}$ & $23.33 \pm 0.67 \mathrm{~A}$ & $73.82 \pm 1.38 \mathrm{~A}$ & $113.63 \pm 5.29 \mathrm{~B}$ \\
P100 & $33.67 \pm 0.88 \mathrm{~B}$ & $10.67 \pm 1.20 \mathrm{~A}$ & $23.00 \pm 0.58 \mathrm{~A}$ & $77.23 \pm 0.66 \mathrm{~B}$ & $97.58 \pm 3.64 \mathrm{~A}$ \\
G100 & $28.00 \pm 0.58 \mathrm{~A}$ & $12.33 \pm 1.20 \mathrm{~A}$ & $26.00 \pm 1.00 \mathrm{~B}$ & $73.23 \pm 0.72 \mathrm{~A}$ & $132.65 \pm 5.69 \mathrm{C}$ \\
\hline
\end{tabular}

${ }^{*}$ Data represent the means of three independent repeats \pm standard deviation. ${ }^{*}$ Capital letters in each column showed significant differences $(P<0.05)$. * P50G50 (sample containing 50\% pectin and 50\% gum); P75G25 (sample containing 75\% pectin and 25\% gum); P25G75 (sample containing $25 \%$ pectin and 75\% gum); P100 (sample containing 100\% pectin) and G100 (sample containing 100\% gum).
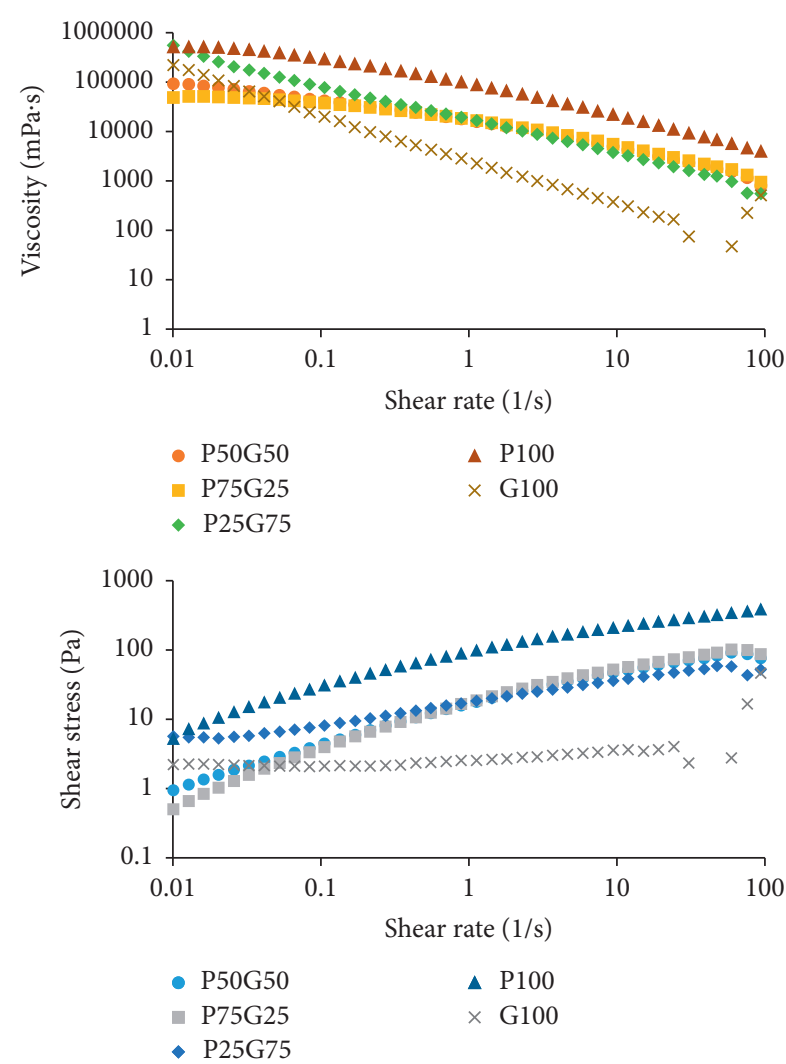

Figure 1: The effects of pectin: gum cordia ratio on apparent viscosity and shear stress of samples.

ingredients and had good antioxidant properties [25, 27]. The results showed that the replacement pectin with gum had no significant effects on the $\mathrm{pH}$ of samples. Also, the same results were reported by Kamal et al. [28]. They reported that addition gelatin has no significance on the $\mathrm{pH}$ of the jelly and the $\mathrm{pH}$ of all samples was around 4 . The addition of gum had no significant effects on the sugar content of samples. DE of the sample significantly decreased with the addition of gum concentration. This is due to the higher degree of esterification of pectin.

3.3. Color. Color of food products is an important quality factor for consumer and usually its effects on the anticipation of people about quality and color parameters [29]. Table 3 reported the lightness $(L *)$, redness $(a *)$, yellowness $(b *)$, color changes $(\Delta \mathrm{E})$, and yellow index
(YI) of apple jelly samples as a main color parameter. Lightness $(L *)$ of apple jelly samples was decreased after the addition of gum cordia (Table 3 ) which was due to the presence of pigments in the gum. Kamal et al. [28] reported that gelatin concentrations had significant effects on the decrease of the $L *$ value of jelly. The addition of gum had no significant effects on the Redness values $(a *)$ of samples. Mutlu et al. [18] reported that gelatin concentration had no significant $(P>0.05)$ effects on the Redness values $(a *)$ of jelly. Yellowness values $(b *)$ were observed to increase with the addition of gum concentration. The results of $\Delta \mathrm{E}$ showed that with the addition of gum concentration, $\Delta \mathrm{E}$ was decreased. Also, YI of the sample showed that with an increase in gum concentration, these parameters were increased. Changes in color parameters are due to some pigments in the gum cordia [30].

3.4. Viscosity Properties. The results in Figure 1 show apple jelly samples had shear-thinning behaviors. The same results about shear-thinning behaviors of jelly were reported by Prakash et al. [31] and Figueroa and Genovese [21]. High molecular weight, the aggregated state, and hydrogen bonds between polymer chains are mainly responsible for the shear-thinning behavior of polysaccharides [32]. Shearthinning properties of biopolymers is an important and key parameter in the food industry, during some food processing such as pumping and filling; these properties are very useful. The higher viscosity at lower shear rates leads to a desirable mouthfeel during mastication [33]. The apparent viscosity of P50G50, P75G25, P25G75, P100, and G100 at the shear rate of $19.1 \mathrm{~s}^{-1}$ and $25^{\circ} \mathrm{C}$ was $3161.80,3519.80,2296.30,13222$, and 189.99 MPa.s, respectively. Prakash et al. [31] reported that a combination of guar gum and pectin had higher effects on the viscosity of jellies. Also, they reported that higher viscosity is a suitable property in the jelly formulations.

3.5. Rheological Properties. Jelly is one of the foods in the class of viscoelastic materials, and the rheological parameter of this food can be evaluated by a dynamic rheological method. The findings of frequency sweep analysis are shown in Figure 2. Three different types of systems, such as gel, concentrated solution, and dilute solution, can be studied by the frequency sweep test. For gel systems, storage moduli are higher than loss moduli over the applied frequency range. In dilute solutions, loss moduli dominate storage moduli which 


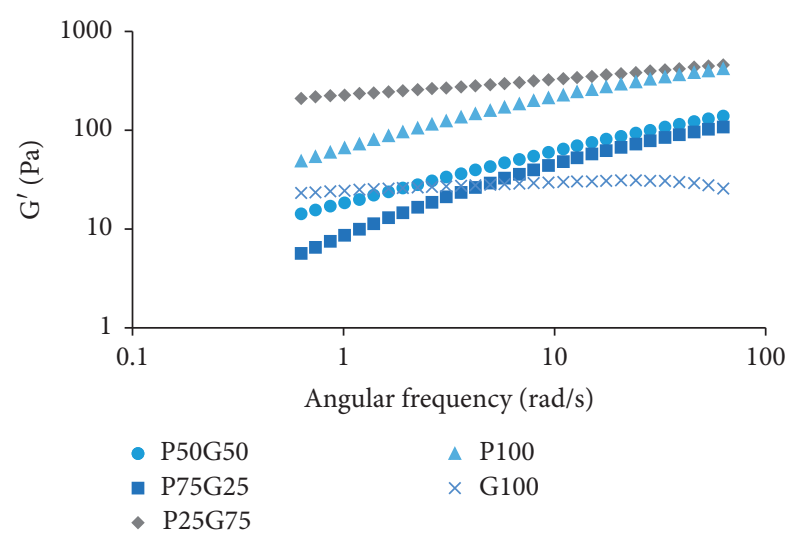

(a)

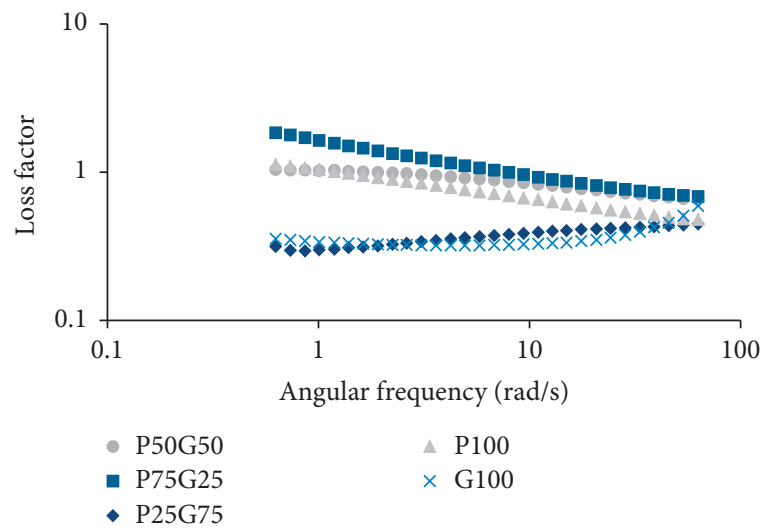

(c)

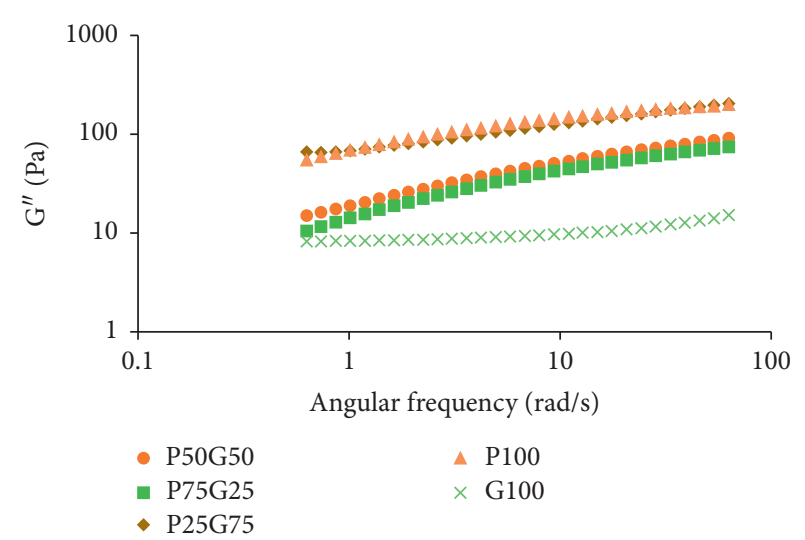

(b)

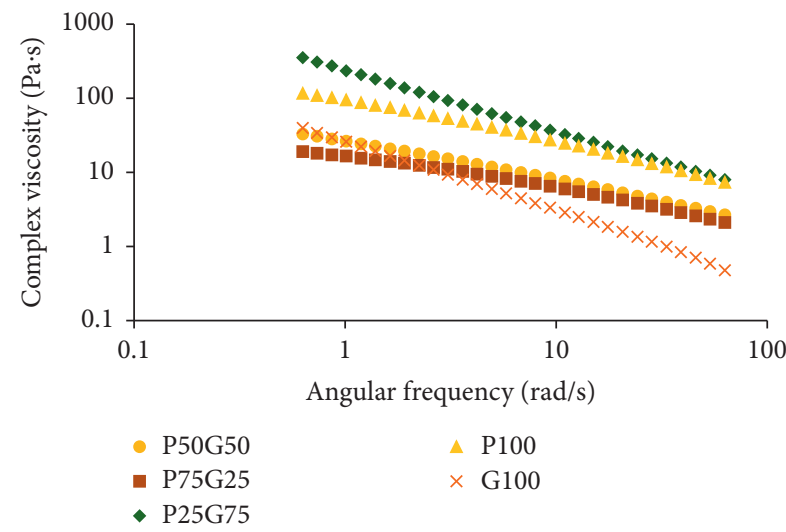

(d)

FIgURE 2: The effects of pectin: gum ratio on storage $\left(G^{\prime}\right)$, loss $\left(G^{\prime \prime}\right)$ moduli, Tan $\delta$, and complex viscosity of samples.

become close to each other at higher frequencies. In concentrated systems, storage moduli are lower than loss moduli at low frequency and crossover each other in the middle range of frequency [34]. The loss $\left(G^{\prime \prime}\right)$ and storage $\left(G^{\prime}\right)$ moduli of different samples showed relatively similar dependency on the applied frequency range. A decrease in $G^{\prime}$ was observed after replacement with gum indicating the low elastic character of gum. Also, the highest loss $\left(G^{\prime \prime}\right)$ and storage $\left(G^{\prime}\right)$ moduli was observed in the P25G75. The higher intermolecular interactions and entanglements between gum cordia chains and pectin could reinforce the biopolymeric network. The data of frequency sweep are in high agreement with those of apparent viscosity. In the P25G75 sample, apparent viscosity and frequency sweep parameters $\left(G^{\prime \prime}, G^{\prime}\right.$, and complex viscosity) were highest.

Tan $\delta$ is the ratio of loss moduli $\left(G^{\prime \prime}\right)$ to storage $\left(G^{\prime}\right)$ moduli (Figure $2(\mathrm{c})$ ). When $\tan \delta$ is $<1$, samples have elastic behavior and when $\tan \delta$ is $>1$, samples have viscous behavior. The system is not a real gel when $\tan \delta$ is higher than 0.1 [35]. The results, reported in Figure 2(c), indicate the presence of weak gel structure (or dominant elastic behavior) in a wide range of applied frequency in samples containing 75 and $100 \%$ gum. The solid-like behavior of samples was similarly reported by Garrido et al. [36].

A decrease in complex viscosity $(\eta *)$ of different samples was reported by increasing the angular frequency
(Figure 2(d)), mainly due to the macromolecules connections and chains entanglements disruption. This behavior shows the shear-thinning behavior of apple jelly. Similar observations about decreasing complex viscosity were reported by Garrido et al. [36] and Figueroa and Genovese [21].

3.6. Textural Properties. Texture analysis can be divided into two instrumental and sensorial technique. Our study applied TPA in order to study the textural characterization of apple jelly [37]. The effects of pectin: gum ratio $(0: 100,25: 75,50$ : 50, 75:25 and 100:0) on textural properties (Hardness, Cohesiveness, Springiness, Gumminess, and Chewiness) of apple jelly were reported in Table 4. The results showed that with an increase in gum concentration, gel formation potential significantly decreased and in the sample containing $100 \%$ gum was liquid. The highest Hardness (2329.52 g), Gumminess (1298.60), and Chewiness (1212.59) were related to the sample containing $100 \%$ pectin. This phenomenon is due to the higher gel formation ability of pectin in comparison with gum. Similar results were reported by Slavutsky and Bertuzzi [38] and Ibáñez et al. [39]. The results showed that there are not any significant differences in Springiness. The highest Cohesiveness properties were related to the P75G25 sample. 
TABLE 4: The effects of pectin: gum ratio on textural properties of samples.

\begin{tabular}{lccccc}
\hline & Hardness $(\mathrm{g})$ & Cohesiveness & Springiness $(\mathrm{g})$ & Gumminess & Chewiness \\
\hline P50G50 & $751.79 \pm 47.64 \mathrm{C}$ & $0.58 \pm 0.00 \mathrm{~B}$ & $0.88 \pm 0.05 \mathrm{~A}$ & $433.67 \pm 27.40 \mathrm{C}$ & $384.20 \pm 47.22 \mathrm{C}$ \\
P75G25 & $1796.24 \pm 91.72 \mathrm{~B}$ & $0.62 \pm 0.00 \mathrm{~A}$ & $0.88 \pm 0.04 \mathrm{~A}$ & $1119.84 \pm 52.51 \mathrm{~B}$ & $981.47 \pm 86.32 \mathrm{~B}$ \\
P25G75 & $207.21 \pm 14.93 \mathrm{D}$ & $0.45 \pm 0.05 \mathrm{~B}$ & $0.95 \pm 0.01 \mathrm{~A}$ & $92.74 \pm 3.13 \mathrm{D}$ & $87.78 \pm 3.95 \mathrm{D}$ \\
P100 & $2329.52 \pm 131.09 \mathrm{~A}$ & $0.56 \pm 0.01 \mathrm{~B}$ & $0.93 \pm 0.03 \mathrm{~A}$ & $1298.60 \pm 98.38 \mathrm{~A}$ & $1212.59 \pm 128.46 \mathrm{~A}$ \\
\hline
\end{tabular}

${ }^{*}$ Capital letters in each column showed significantly differences $(P<0.05) .{ }^{*}$ P50G50 (sample containing 50\% pectin and 50\% gum); P75G25 (sample containing 75\% pectin and 25\% gum); P25G75 (sample containing 25\% pectin and 75\% gum); P100 (sample containing $100 \%$ pectin) and G100 (sample containing $100 \%$ gum).
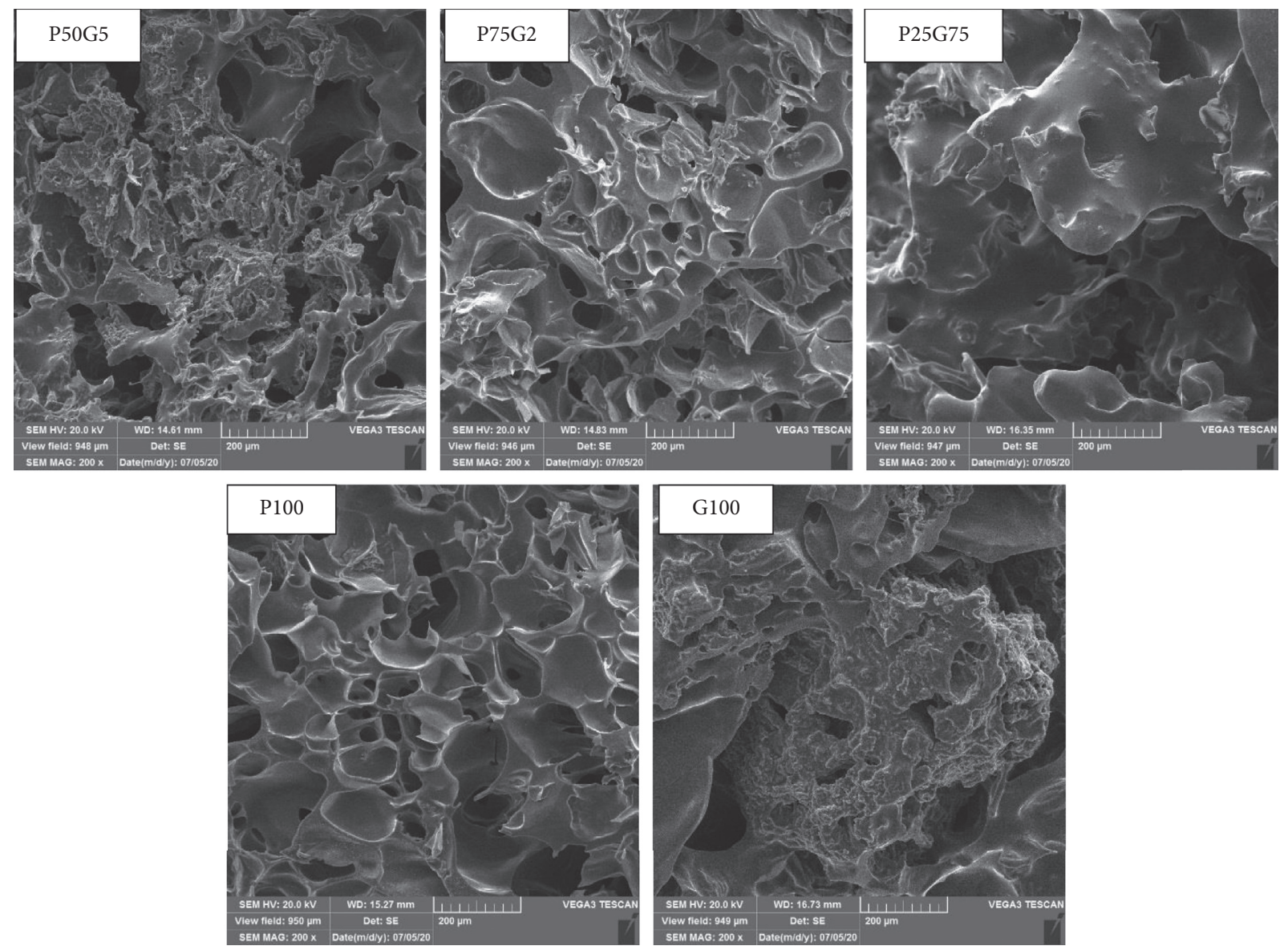

FIGURE 3: The effects of pectin: gum ratio on the microstructure of samples.

TABLE 5: The effects of pectin: gum ratio on the sensorial properties of samples.

\begin{tabular}{lccccc}
\hline & Odor & Texture & Taste & Appearance & Overall \\
\hline P50G50 & $4.75 \pm 0.25 \mathrm{AB}$ & $3.75 \pm 0.25 \mathrm{AB}$ & $3.50 \pm 0.50 \mathrm{~B}$ & $3.75 \pm 0.25 \mathrm{~B}$ & $3.75 \pm 0.25 \mathrm{~B}$ \\
P75G25 & $5.00 \pm 0.00 \mathrm{~B}$ & $3.75 \pm 0.25 \mathrm{AB}$ & $4.00 \pm 0.41 \mathrm{~B}$ & $4.50 \pm 0.29 \mathrm{BC}$ & $4.50 \pm 0.29 \mathrm{C}$ \\
P25G75 & $4.00 \pm 0.41 \mathrm{~A}$ & $4.00 \pm 0.00 \mathrm{BC}$ & $3.50 \pm 0.29 \mathrm{~B}$ & $4.50 \pm 0.29 \mathrm{C}$ & $4.25 \pm 0.25 \mathrm{C}$ \\
P100 & $5.00 \pm 0.00 \mathrm{~B}$ & $5.00 \pm 0.00 \mathrm{C}$ & $4.25 \pm 0.48 \mathrm{~B}$ & $4.75 \pm 0.25 \mathrm{C}$ & $4.75 \pm 0.25 \mathrm{C}$ \\
G100 & $4.00 \pm 0.41 \mathrm{~A}$ & $3.00 \pm 0.71 \mathrm{~A}$ & $2.25 \pm 0.48 \mathrm{~A}$ & $2.25 \pm 0.25 \mathrm{~A}$ & $2.75 \pm 0.25 \mathrm{~A}$ \\
\hline
\end{tabular}

* Data represent the means of three independent repeats \pm standard deviation. ${ }^{*}$ Capital letters in each column showed significant differences $(P<0.05)$. * P50G50 (sample containing 50\% pectin and 50\% gum); P75G25 (sample containing 75\% pectin and 25\% gum); P25G75 (sample containing 25\% pectin and $75 \%$ gum); P100 (sample containing 100\% pectin) and G100 (sample containing 100\% gum).

3.7. Microstructure. The microstructure of the samples is shown in Figure 3. The sample containing 100 and $75 \%$ pectin had a uniform and regular structure, but with the addition of gum concentration, uniformity was decreased.
Pectin samples present an open heterogeneous and tridimensional structure. This porous structure is obtained by the water molecules displacement during the drying process required by SEM observation [38]. Soares et al. [40] and 
Oliveira Cardoso et al. [41] reported similar structures for hydrogels.

3.8. Sensorial Properties. Critical sensory attributes of the samples, including appearance, odor, texture, taste, and consumer acceptance, were determined by panelists [37]. Sensory properties samples are reported in Table 5. The results showed that sensory properties were significantly $(P>0.05)$ influenced by the gum cordia dose. The results showed sensorial properties of the sample containing $75 \%$ gum cordia was similar to the sample containing $100 \%$ pectin. This sample had a high score in texture, taste, appearance, and overall acceptability.

\section{Conclusion}

Today, consumers like healthier foods fortified with an antioxidant component such as phenolic ingredients. Our findings show that gum cordia can be applied as a stabilizer to production apple jelly. The total phenol content of the sample significantly increased with the addition of gums. Gum cordia had a significant influence on the improved viscoelastic parameters of the apple jellies. The rheological properties showed that the sample containing $75 \%$ gum cordia was a similar sample to control. Also, the sensorial properties showed that a sample containing $75 \%$ gum cordia had high score in texture, taste, appearance, and overall acceptability. The results suggested that gum cordia as a polymer can be successfully employed for the formulation of jelly for improving the technofunctional properties of jelly.

\section{Data Availability}

All data and analyses were reported as figures and tables in the manuscript.

\section{Conflicts of Interest}

The authors declare that they do not have any conflicts of interest.

\section{Acknowledgments}

This work was financially supported by the Azad University of Kazerun.

\section{References}

[1] M. A. Haq, A. Hasnain, F. A. Jafri, M. F. Akbar, and A. Khan, "Characterization of edible gum cordia film: effects of beeswax," LWT-Food Science and Technology, vol. 68, pp. 674-680, 2016.

[2] K. Mahmood, M. S. Alamri, M. A. Abdellatif, S. Hussain, and A. A. A. Qasem, "Wheat flour and gum cordia composite system: pasting, rheology and texture studies," Food Science and Technology, vol. 38, no. 4, pp. 691-697, 2018.

[3] M. F. Tahir, S. A. Bukhari, F. Anjum, M. Qasim, H. Anwar, and S. A. R. Naqvi, "Purification and modification of Cordia myxa gum to enhance its nutraceutical attribute as binding agent," Pakistan Journal of Pharmaceutical Sciences, vol. 32, no. 5, pp. 2245-2250, 2019.
[4] M. A. Haq, M. J. Alam, and A. Hasnain, "Gum Cordia: a novel edible coating to increase the shelf life of Chilgoza (Pinus gerardiana)," LWT-Food Science and Technology, vol. 50, no. 1, pp. 306-311, 2013.

[5] A. Rafe and H. Masood, "The rheological modeling and effect of temperature on steady shear flow behavior of Cordia abyssinica gum," Journal of Food Processing \& Technology, vol. 5, no. 3, p. 1, 2014.

[6] M. Kopjar, A. Pichler, J. Turi, and V. Piližota, "Influence of trehalose addition on antioxidant activity, colour and texture of orange jelly during storage," International Journal of Food Science \& Technology, vol. 51, no. 12, pp. 2640-2646, 2016.

[7] R. M. Schweiggert, E. Vargas, J. Conrad et al., "Carotenoids, carotenoid esters, and anthocyanins of yellow-, orange-, and red-peeled cashew apples (Anacardium occidentale L.)," Food Chemistry, vol. 200, pp. 274-282, 2016.

[8] A. Iqbal, R. Farheen, and R. Parween, "Comparative evaluation of total iron, vitamin $\mathrm{C}$ and total phenolic contents in fresh juices of apple (Malus pumilla) grown in Pakistan," FUUAST Journal of Biology, vol. 9, no. 1, pp. 29-32, 2019.

[9] A. A. Zielinski, D. M. Zardo, A. Alberti et al., "Effect of cryoconcentration process on phenolic compounds and antioxidant activity in apple juice," Journal of the Science of Food and Agriculture, vol. 99, no. 6, pp. 2786-2792, 2019.

[10] M. B. Lima, F. M. Domingos, J. J. F. d. J. Lima et al., "Characterization and influence of hydrocolloids on low caloric orange jellies," Emirates Journal of Food and Agriculture, vol. 31, no. 1, 2019.

[11] Y. Monroy, S. G. Rivero, and M. A. Garcia, "Functional jelly beans based on hydrocolloids and citrus cremogenates," Journal of Multidisciplinary Engineering Science and Technology, vol. 4, no. 10, 2017.

[12] S. D. Patil, M. J. Gupta, K. S. Kote, and R. Rajendran, "Formulation of novel medicated jellies for treatment of mouth ulcer," Asian Journal of Pharmacy and Technology, vol. 9, no. 4, pp. 241-243, 2019.

[13] P. A. P. Pereira, V. R. Souza, M. A. Vieira et al., "Sugar-free guava preserve: influence of additives on textural properties," International Food Research Journal, vol. 24, no. 6, pp. 2377-2386, 2017.

[14] S. A. Mir, M. A. Shah, H. R. Naik, and I. A. Zargar, "Influence of hydrocolloids on dough handling and technological properties of gluten-free breads," Trends in Food Science \& Technology, vol. 51, pp. 49-57, 2016.

[15] Á. Periche, M. L. Castelló, A. Heredia, I. Escriche, and S. tevia rebaudiana, "Stevia rebaudiana, oligofructose and isomaltulose as sugar replacers in marshmallows: stability and antioxidant properties," Journal of Food Processing and Preservation, vol. 40, no. 4, pp. 724-732, 2016.

[16] G. W. Latimer, Official Methods of Analysis of AOAC International, AOAC International, Rockville, MD, USA, 2016.

[17] G. S. Abrol, R. Pal, A. Pandey, and S. Sharma, "Effect of drying on physico-chemical properties of fig fruit (Ficus carica L.) variety dinkar," International Journal of Food and Fermentation Technology, vol. 9, no. 1, pp. 47-52, 2019.

[18] C. Mutlu, S. A. Tontul, and M. Erbaş, "Production of a minimally processed jelly candy for children using honey instead of sugar," LWT, vol. 93, pp. 499-505, 2018.

[19] E. R. Pinheiro, L. V. Gonzaga, I. M. Silva et al., "Optimization of extraction of high-ester pectin from passion fruit peel (Passiflora edulis flavicarpa) with citric acid by using response surface methodology," Bioresource Technology, vol. 99, no. 13, pp. 5561-5566, 2008. 
[20] M. R. Firuzi, M. Niakousari, M. H. Eskandari et al., "Incorporation of pomegranate juice concentrate and pomegranate rind powder extract to improve the oxidative stability of frankfurter during refrigerated storage," $L W T$, vol. 102, pp. $237-245,2019$.

[21] L. E. Figueroa and D. B. Genovese, "Fruit jellies enriched with dietary fibre: development and characterization of a novel functional food product," $L W T$, vol. 111, pp. 423-428, 2019.

[22] H. H. Gahruie, M. H. Eskandari, S. M. H. Hosseini, and P. Van der Meeren, "Study on hydrophobic modification of basil seed gum-based (BSG) films by octenyl succinate anhydride (OSA)," Carbohydrate Polymers, vol. 219, pp. 155$161,2019$.

[23] J. Nwosu, L. O. Udeozor, C. C. Ogueke, N. Onuegbu, G. C. Omeire, and I. S. Egbueri, "Extraction and utilization of pectin from purple star-apple (Chrysophyllum cainito) and African star-apple (Chrysophyllum delevoyi) in jam production," Austin Journal of Nutrition and Food Science, vol. 1, no. 1, pp. 1003-1009, 2014.

[24] J. T. C. L. Toneli, F. E. X. Mürr, P. Martinelli, I. M. Dal Fabbro, and K. J. Park, "Optimization of a physical concentration process for inulin," Journal of Food Engineering, vol. 80, no. 3, pp. 832-838, 2007.

[25] S. Keshani-Dokht, Z. Emam-Djomeh, M.-S. Yarmand, and M. Fathi, "Extraction, chemical composition, rheological behavior, antioxidant activity and functional properties of Cordia myxa mucilage," International Journal of Biological Macromolecules, vol. 118, pp. 485-493, 2018.

[26] M. Chaharlang and V. Samavati, "Steady shear flow properties of Cordia myxa leaf gum as a function of concentration and temperature," International Journal of Biological Macromolecules, vol. 79, pp. 56-62, 2015.

[27] M. A. Haq and A. Hasnain, "Antioxidant containing gum cordia coatings for control of peanut oxidation," Journal of Food Processing and Preservation, vol. 38, no. 3, pp. 896-904, 2014.

[28] T. Kamal, Y. Song, T. Zhang, B.-W. Zhu, and M. Tan, "Effect of hydrocolloid and processing potentiality on water migration in apple jellies of Yinduqing cultivar," $L W T$, vol. 98, pp. 381-389, 2018.

[29] S. C. S. R. d. Moura, P. E. d. Rocha Tavares, S. P. M. Germer, A. L. A. C. Nisida, A. B. Alves, and A. S. Kanaan, "Degradation kinetics of anthocyanin of traditional and low-sugar blackberry jam," Food and Bioprocess Technology, vol. 5, no. 6, pp. 2488-2496, 2012.

[30] H. A. Pawar and P. Jadhav, "Isolation, characterization and investigation of Cordia dichotoma fruit polysaccharide as a herbal excipient," International Journal of Biological Macromolecules, vol. 72, pp. 1228-1236, 2015.

[31] K. Prakash, V. Satyanarayana, H. Nagiat, A. Fathi, A. Shanta, and A. Prameela, "Formulation development and evaluation of novel oral jellies of carbamazepine using pectin, guar gum, and gellan gum," Asian Journal of Pharmaceutics, vol. 8, no. 4, pp. 241-249, 2014.

[32] B. Vardhanabhuti and S. Ikeda, "Isolation and characterization of hydrocolloids from monoi (Cissampelos pareira) leaves," Food Hydrocolloids, vol. 20, no. 6, pp. 885-891, 2006.

[33] L. N. Sadar, "Rheological and textural characteristics of copolymerized hydrocolloidal solutions containing curdlan gum," Master thesis, University of Maryland, College Park, MA, USA, 2004.

[34] M. Kutz, Handbook of Farm, Dairy and Food Machinery Engineering, Academic Press, Cambridge, MA, USA, 2nd edition, 2013.
[35] I. G. Mandala, T. P. Savvas, and A. E. Kostaropoulos, "Xanthan and locust bean gum influence on the rheology and structure of a white model-sauce," Journal of Food Engineering, vol. 64, no. 3, pp. 335-342, 2004.

[36] J. I. Garrido, J. E. Lozano, and D. B. Genovese, "Effect of formulation variables on rheology, texture, colour, and acceptability of apple jelly: modelling and optimization," LWT-Food Science and Technology, vol. 62, no. 1, pp. 325332, 2015.

[37] H. H. Gahruie, M. H. Eskandari, and G. Mesbahi, "Development of functional yogurt fortified with wheat germ and strawberry as functional ingredients," Progress in Nutrition, vol. 21, no. 1, pp. 388-398, 2019.

[38] A. M. Slavutsky and M. A. Bertuzzi, "Formulation and characterization of hydrogel based on pectin and brea gum," International Journal of Biological Macromolecules, vol. 123, pp. 784-791, 2019.

[39] R. A. Ibáñez, D. S. Waldron, and P. L. H. McSweeney, "Effect of pectin on the composition, microbiology, texture, and functionality of reduced-fat Cheddar cheese," Dairy Science \& Technology, vol. 96, no. 3, pp. 297-316, 2016.

[40] P. A. G. Soares, J. R. P. C. d. Seixas, P. B. S. Albuquerque et al., "Development and characterization of a new hydrogel based on galactomannan and $\kappa$-carrageenan," Carbohydrate Polymers, vol. 134, pp. 673-679, 2015.

[41] V. M. d. Oliveira Cardoso, B. Stringhetti Ferreira Cury, R. C. Evangelista, and M. P. Daflon Gremião, "Development and characterization of cross-linked gellan gum and retrograded starch blend hydrogels for drug delivery applications," Journal of the Mechanical Behavior of Biomedical Materials, vol. 65 , pp. 317-333, 2017. 